\title{
Stress analysis of lap joints involving natural fibre reinforced interface layers
}

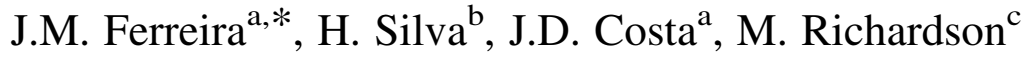 \\ ${ }^{a}$ Department of Mechanical Engineering, University of Coimbra, Polo II, Coimbra 3030, Portugal \\ ${ }^{\mathrm{b}}$ Department of Mechanical Engineering, ESTV, IPV, Viseu, Portugal \\ ${ }^{\mathrm{c}}$ Department of Mechanical and Design Engineering, Portsmouth University, Portsmouth, UK
}

Received 7 May 2003; revised 2 April 2004; accepted 30 April 2004

Available online 10 June 2004

\begin{abstract}
This paper is concerned with a fatigue study of composite adhesive lap joints. The tests were carried out on specimen joints manufactured using different stacking sequences: solely bi-directional woven E-glass fibres and polypropylene composites; and hybrid stacked composites. The main objective of the work was to improve the fatigue strength using hybrid fibre composites with a polypropylene/hemp natural fibre layer adjacent to the bond interface which was expected to produce more uniform stresses in transient regions. The adhesive used was a Bostik 7452 (Rubber and Plastics Grade) ethyl cyanoacrylate type. The results are presented in the form of curves of stress amplitude versus number of cycles to failure. The failure mechanisms (together with peak stresses in the regions adjacent to the bond obtained by finite elements analysis and experimental values of interlaminar toughness) are discussed in order to explain the lower fatigue strength in hybrid stacked joints than in the original thermoplastic composite joints (contrary what was expected) and the decrease with the natural fibre content. (C) 2004 Elsevier Ltd. All rights reserved.
\end{abstract}

Keywords: B. Fatigue; Hybrid composites

\section{Introduction}

Bonded joints are able to join different materials in complex shapes with a smoother appearance and promoting fewer stress concentrations than other methods of joining, such as bolting, riveting and spot welding. Bonded joints have several advantages, namely, there is no need to produce holes which are stress concentrators, corrosion problems are reduced, the distribution of stresses is more uniform and they are able to join radically different materials.

However, the parts once joined cannot be separated, residual stresses can appear due to distinct thermal expansion coefficients, materials can have low resistance to high temperature and fire, and degradation with time can occur.

In most cases at moderate stress levels fatigue failure of bonded joints initiates at the adhesive [1,2]. The initiation of small cracks at the edges constitutes the major part of

\footnotetext{
* Corresponding author. Tel.: +351-239790700; fax: + 351-239790701.

E-mail address: martins.ferreira@dem.uc.pt (J.M. Ferreira).
}

the fatigue life [3]. However, recent work of the authors [4] in joints with polypropylene/glass fibres concludes that the separation of the polypropylene and the glass fibre in the interface adjacent to the adhesive is the most probable failure mode for well-bonded joints. The fatigue life is also strongly influenced by the profile of the joint edges and consequently the stress distribution modifications in the adhesive region.

Different damage criteria involve stress and strain distributions to predict load limit for the bonded joints. Several parameters influence the mechanical resistance of bonded joints namely, the materials (fibre, matrix and glue, the volumetric fraction of fibre, the lay-up sequencecombination of ply orientations, stacking sequence-the order in which the plies are placed through the thickness, the adhesion of fibre/matrix), the manufacturing procedure (preparation of surfaces prior to bonded, etc.) the geometry of the joint (thickness of the glue and adherends [5], overlap length [6]), loading (loading rate) and environment (temperature, humidity). The single lap joint is known to be quite sensitive to changes in geometrical parameters [7]. Also, several mechanisms can be responsible for the failure 
of the material, which can grouped into failure of adherends (delamination, failure of the fibres, etc.), failure at the interface glue/adherends, and failure of the glue (cohesive failure).

The objective of this work was to study the fatigue strength of a hybrid composite with a polypropylene/hemp natural fibre layer adjacent to the bond interface. This was expected to result in more uniform stresses in the transient regions and eventually to less sensitivity to fatigue failure. Economical and ecological benefits were also expected.

For this study a single lap shear joint was chosen. This type of joint promotes low fatigue performance because of the high shear and peel stress concentrations that arise in the adhesive layer at the ends of the overlap [8].

\section{Materials and experimental procedures}

Assuming that the interface between the adhesive and the main composite plate was the critical failure zone [4] surface preparation and composite stacking was carefully studied. Two types of plate were manufactured for this study. In one of them all the layers were solely Vetrotex "Twintex T PP" and had one of the fibre orientations coinciding with the load direction, $0^{\circ} / 0^{\circ} / 0^{\circ} / 0^{\circ} / 0^{\circ} / 0^{\circ} / 0^{\circ}$. The other was a hybrid stacking sequence with six thermoplastic composite layers similar to first one followed by a surface layer composed of a random distribution of natural fibre (hemp) and a polypropylene matrix sheet. This layer of about $0.6 \mathrm{~mm}$ thickness was produced as part of the moulding process.

Composite sheets were processed at $190{ }^{\circ} \mathrm{C}$ in a mould under a compression pressure of $5 \mathrm{bar}$, for $10 \mathrm{~min}$. The overall dimensions of the plates were $160 \times 250 \times 3 \mathrm{~mm}^{3}$ with a fibre volume fraction of 0.338 , as reported by the manufacturer. Two fibre volume fractions were used in the $\mathrm{PP} /$ natural fibre layer, with the values obtained experimentally as: 0.12 and 0.15 .

The specimens were manufactured as $20 \mathrm{~mm}$ wide bars cut from the plates. The geometry and dimensions of the specimens are shown in Fig. 1. The adhesive used was Bostik 7452-Super Glue 4, Rubber and Plastics Grade ethyl cyanoacrylate type, while the primer was Bostik 7480-Super Glue 4 based on $n$-heptane. To obtain good adhesion very careful surface preparation was necessary. Table 1 summarises the two preparation techniques which produced the best results as well as the layer stacking sequences of the composites analysed. One of these techniques was first to clean the surface by an ultrasonic process and then to put the specimens for $1 \mathrm{~h}$ in a bath of trichlorethylene. The other technique (referred to as etch cleaning) involving the use of one acid mixture prepared by mixing in the following order: two volumes of distilled water, two volumes of orthophosphoric acid, five volumes of concentrated sulphuric acid. The mixture was then allowed to cool before adding $1 \mathrm{~g}$ potassium

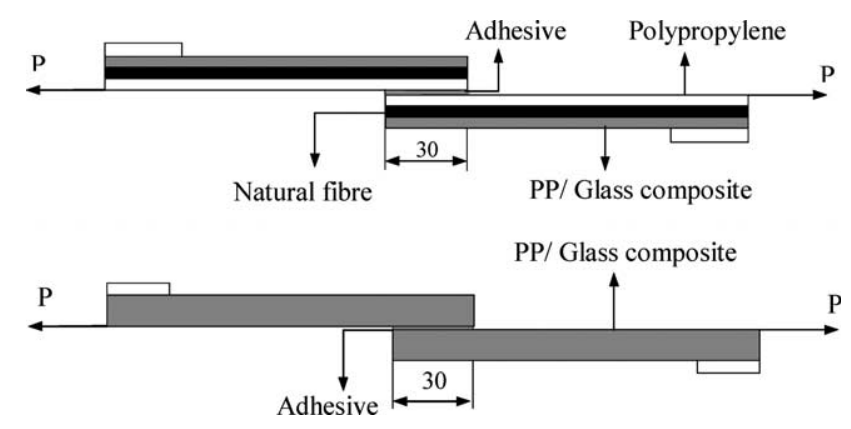

Fig. 1. Geometry and dimensions of the specimens (dimensions in $\mathrm{mm}$ ).

permanganate powder per $100 \mathrm{ml}$ of etchant poured through a glass funnel into a conical flask containing the acid mixture as it was being stirred using a magnetic stirrer at high speed. This was continued for $30 \mathrm{~min}$ to ensure complete dissolution of the potassium permanganate.

The bond thickness was kept similar for all the specimens. The samples were visually checked before testing. An average bond thickness of $0.1 \mathrm{~mm}$ and a standard deviation of 0.018 were obtained from experimental measurements. The reduced dispersion obtained meant that this parameter within a controlled range did not have a significant influence on the fatigue behaviour of adhesive joints [9].

The tensile properties were obtained using an electromechanical Instron Universal Testing machine. The fatigue tests were carried out on a servo-hydraulic Instron machine in constant amplitude load. All fatigue tests were performed in tension with stress ratio of 0.025 and a frequency of $5 \mathrm{~Hz}$, at room temperature. During the fatigue tests negligible temperature rises of the specimens were obtained contrary to that observed by the authors for the adherent material at $10 \mathrm{~Hz}[10,11]$.

\section{Results and discussion}

Table 1 presents the average values and the standard deviation for the three tests at each condition of the ultimate shear strength for the four series previously selected. These results indicate no significant scatter and revealed that the surface preparation involving a bath of trichlorethylene produced stronger joints than using the etching technique. The introduction of the PP/natural fibre layer adjacent to the bond reduced the strength, with the effect increasing with natural fibre content. Moderate results were obtained when the natural fibre was put just in contact with the surface, probably as consequence of poor adhesion between the hemp natural fibres and the bonding material.

Fatigue results, in terms of the maximum stress against the number of cycles to failure are shown in Fig. 2. These results show that the fatigue strength was lower in the hybrid joints than in the original thermoplastic composite joints and exhibited a significant decrease when the natural fibre content increased from 12 to $15 \%$. 
Table 1

Summary of tested joints and average static strength

\begin{tabular}{|c|c|c|c|c|}
\hline Reference & Composite stacking (outward side to adhesive surface) & Surface treatment & Mean shear strength $(\mathrm{MPa})$ & Standard deviation \\
\hline SC1 & Twintex (7 layers) & Ultra-sonic + trichlorethylene & 12.02 & 0.170 \\
\hline $\mathrm{SC} 2$ & Twintex (7 layers) & Etching & 11.62 & 0.014 \\
\hline $\mathrm{HC} 1$ & Twintex (6 layers)/NF(1 layer)/PP(1 layer) & Ultra-sonic + trichlorethylene & 10.2 & 0.015 \\
\hline $\mathrm{HC} 2$ & Twintex (6 layers)/PP(1 layer)/NF(1 layer) & Ultra-sonic + trichlorethylene & 8.46 & 0.311 \\
\hline
\end{tabular}

NF, natural fibre; SC, Twintex solely; HC, hybrid stacking composite; PP, polypropylene.

In order to explain the negative effect of the natural fibre layers, the failed surfaces were studied by microscopy analysis. Fig. 3(a) and (b) exhibit the failure surfaces for hybrid and solely thermoplastic composites, respectively. In solely thermoplastic composites the predominant failure mode is the separation of the polypropylene and the glass fibre in the interface adjacent to the adhesive (Fig. 3(b)). In a few cases this failure can also involve adhesive fracture. For the hybrid joints the easier failure mode is the peel of the interface between $\mathrm{PP} /$ glass fibre and $\mathrm{PP} /$ natural fibre layers (Fig. 3(a)). The predominance of this failure mode is associated with the joint strength decreasing in terms of static or fatigue strength. This can be associated with higher stresses in the transient region and lower fibre cohesive strength associated with natural fibre compared to the glass fibre. These two aspects were studied with the following results.

Interlaminar fracture toughness tests were carried out using double cantilever beam specimens, following ASTM D5528-94a [12], for solely Twintex laminates and laminates composed with alternated layers of a random distribution of natural fibre and a polypropylene matrix. The geometry and dimensions of the double cantilever beam specimens and also a testing view are shown in Fig. 4. The tests were performed in an electromechanical Instron Universal Testing machine in displacement control at a rate of $5 \mathrm{~mm} / \mathrm{min}$.

Composite panels $200 \times 160 \times 3 \mathrm{~mm}^{3}$ were fabricated by hand layup and compression moulding. A Teflon film was placed at the mid plane of the panel to create the initial delamination crack.

The specimens were tested and the load $P$, displacement $\delta$ and the crack length $a$, were registered. The crack length was measured by an optical system. For each load step the crack length was increased by about $5 \mathrm{~mm}$ then the specimen was unloaded.

For each partial loading the maximum load and the corresponding displacement and crack length were obtained, from these the mode I strain release rate $\left(G_{\mathrm{I}}\right)$ was calculated assuming the validity of linear beam theory as a consequence each arm of the double cantilever beam acting as a cantilever beam [13]. The equation used was

$G_{\mathrm{I}}=\frac{3 P \delta}{2 b a^{*}}$ where: $P$ is the maximum load, $\delta$ the opening displacement, $b$ is the width and $a^{*}$ is the corrected crack length to take in account the shear deformation and rotation. $a^{*}$ is derived by $a^{*}=a+\Delta$, where $a$ is the crack length corresponding to maximum load within each step load and $\Delta$ is determined by plotting the cube root of the specimen compliance versus crack length according to a procedure described by Williams [14].

The values obtained for $G_{\mathrm{I}}$ are plotted in Fig. 5 against the crack length for each of the six specimens tested. Also the average values for tests with solely Twintex laminates and natural fibre laminates are superimposed. The average values for natural fibre laminates are about $28 \%$ lower than those obtained for Twintex laminates which are correlated to the decrease of static and the fatigue resistance exhibited by $\mathrm{HC}$ joints.

For the purpose of obtaining the stress distribution along the adhesive joint, a 2D finite element analysis was performed. The geometry was modelled as a 2D plane strain problem, since the joint has a relatively high width. A bond thickness of $0.1 \mathrm{~mm}$ was considered. The boundary conditions are intended to simulate the restrictions imposed by the grips of the testing machine (with no displacements

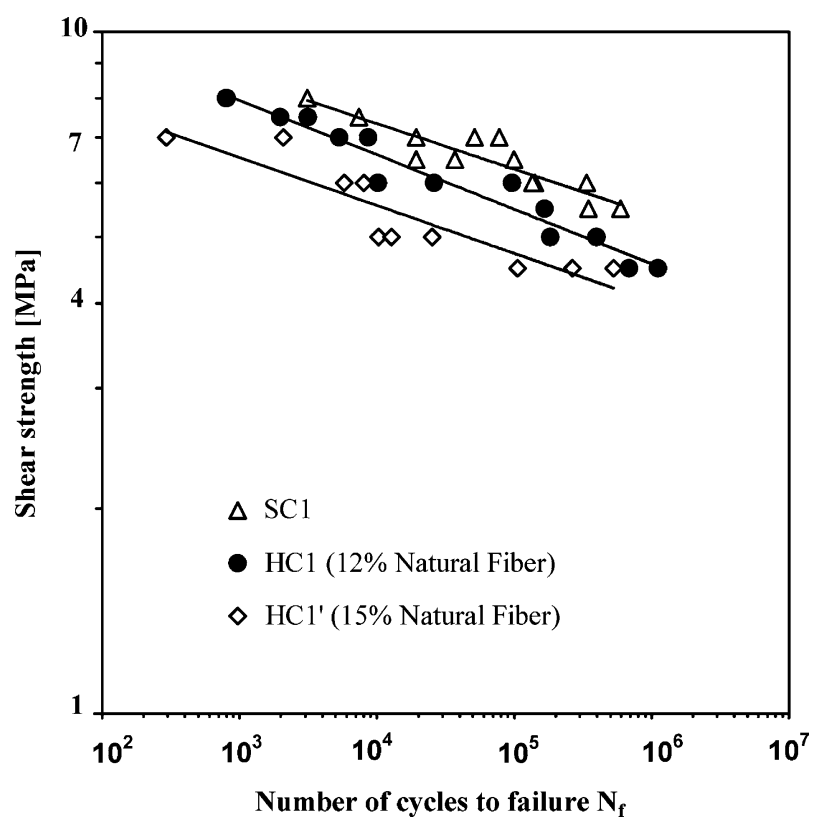

Fig. 2. S-N curves. 

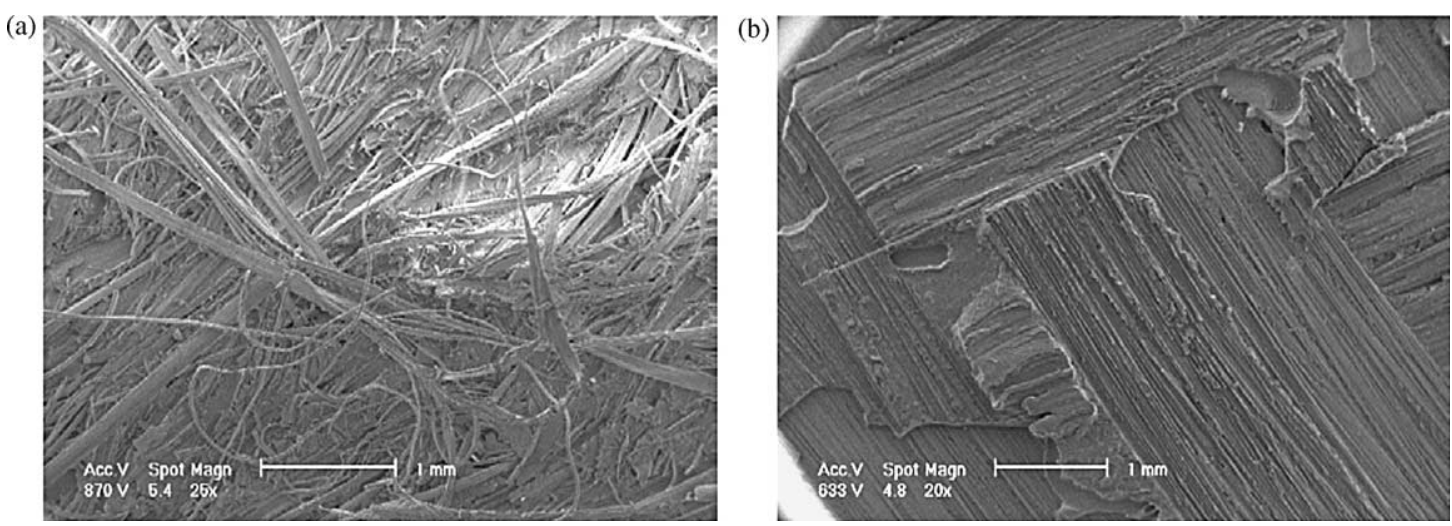

Fig. 3. Failure surfaces. (a) hybrid stacked joint; (b) solely thermoplastic composites joints.

in left grip of Fig. 1 and no vertical displacements in the right grip). It should be noticed that these boundary conditions restrain rigid body movement.

The adherents were assumed to be continuous, homogeneous and with orthotropic linear elastic behaviour. The elastic properties considered are presented in Table 2. The principal directions are presented in Table 2. The adhesive was assumed to be continuous, homogeneous and isotropic with elasto-plastic behaviour. Its tensile properties were obtained by means tensile tests with $1.5 \mathrm{~mm}$ thickness specimens using the NFT-5104 Standard. Young's modulus and Poisson's ratio are $E=956.44 \mathrm{MPa}$ and $\nu=0.446$, respectively. A Ramberg-Osgood equation was fitted to the experimental stress-plastic strain curve:

$\sigma=22.9\left(\varepsilon_{\mathrm{p}}\right)^{0.186}$

where $\sigma$ is the local stress and $\varepsilon_{\mathrm{p}}$ is the plastic strain. Fig. 6 shows the experimental points as well as the fitted curve and its extrapolation for high local strain necessary for the numerical analysis.

The adhesive was assumed to obey the yield criteria of the Von Mises and Prandtl-Reuss flow rule. A kinematic hardening rule was assumed, being the backstress defined by Ziegler's rule.

Young's modulus and Poisson's ratio were obtained experimentally according to the ISO 3268-1978 (F) [15] and ASTM E132-97 [16] Standards, respectively.

The physical model was analysed by a finite element method using a commercial finite element package MARC-MENTAT 2000 [17]. The analysis was carried out assuming large displacements and large strains. Quadrilateral isoparametric elements with eight nodes were considered. Fig. 7 shows one of the finite element meshes considered, which were refined near the corners where stresses and strains vary significantly. Square elements were considered there because this shape gives the best results. Eight elements were considered along the thickness of the adhesive, each with $12.5 \mu \mathrm{m}$. Hildebrand [18] used six quadratic elements and recommended the use of 4-6 elements along the thickness of the adhesive layer to achieve reliable results. Large elements were used far from the corners to reduce the numerical effort. Total numbers of elements and nodes were 24388 and 73901 , respectively.
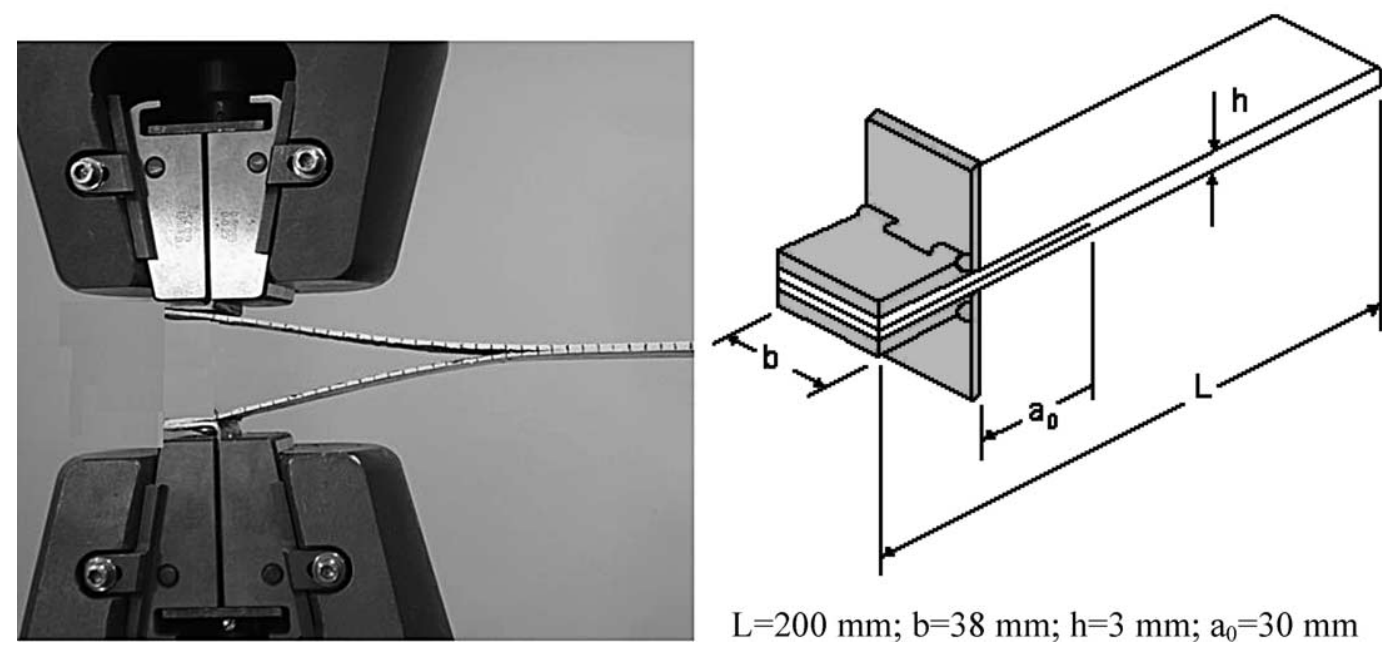

$\mathrm{L}=200 \mathrm{~mm} ; \mathrm{b}=38 \mathrm{~mm} ; \mathrm{h}=3 \mathrm{~mm} ; \mathrm{a}_{0}=30 \mathrm{~mm}$

Fig. 4. Testing view, geometry and dimensions of the double cantilever beam specimens. 


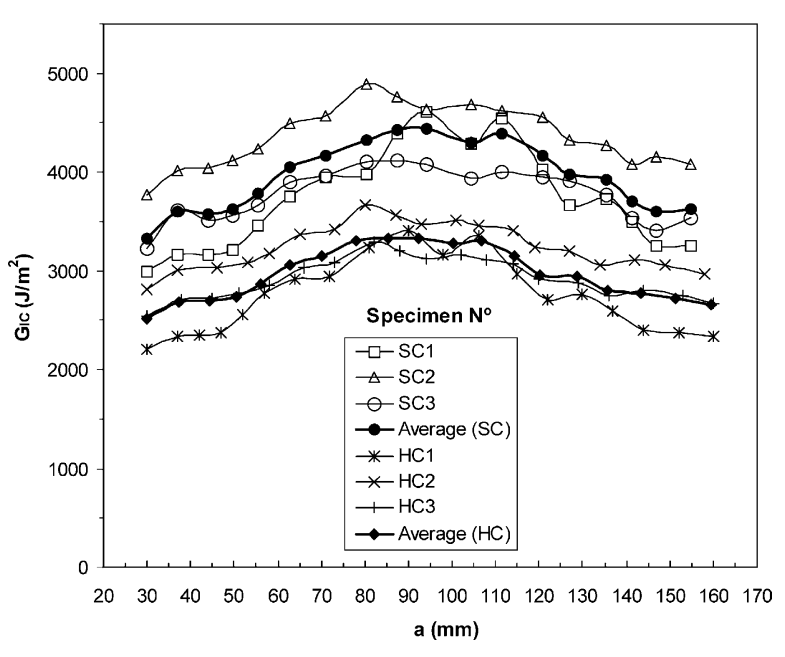

Fig. 5. Interlaminar fracture toughness versus the crack length.

The influence of the convergence limit (CL) of NewtonRaphson iterative process was analysed being obtained good results with $\mathrm{CL} \leq 0.25 \%$.

The results for solely Twintex composite (SC) and hybrid layer composite (HC) are superimposed. In Fig. 8 the Von Mises stresses are plotted along the adhesive in the middle section for two very different loads. Fig. 8(a) was plotted for an axial load of $2 \mathrm{kN}$, which corresponds to near elastic behaviour and Fig. 8(b) for an axial load of $8 \mathrm{kN}$, which correspond to a large plasticity deformation near the failure. For both loads the peak stresses were higher for hybrid stacking than for solely PP/glass fibre composites, being about $9 \%$ for both loads.

Other critical sections are the longitudinal one in the polypropylene/natural fibre layer adjacent to the bond where the transfer loading between the fibre and the polypropylene occurs. This was analysed in a particular section at a distance of $100 \mu \mathrm{m}$ from the interface which seems be

Table 2

Mechanical properties of adherends used in FE study

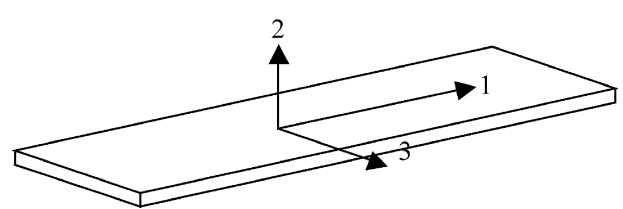

\begin{tabular}{|c|c|c|c|}
\hline Property & $\begin{array}{l}\text { Value for PP/ } \\
\text { glass fibre sheet }\end{array}$ & $\begin{array}{l}\text { Value for } \mathrm{PP} / 12 \% \\
\text { hemp natural } \\
\text { fibre sheet }\end{array}$ & $\begin{array}{l}\text { Calculation } \\
\text { procedure }\end{array}$ \\
\hline$E_{1}(\mathrm{MPa})$ & 17289.2 & 3370 & Experimental values \\
\hline$E_{2}(\mathrm{MPa})$ & 1500 & 1500 & Typical value for PP \\
\hline$E_{3}(\mathrm{MPa})$ & 17289.2 & 3370 & $=E_{1}$ \\
\hline$\nu_{12}=\nu_{32}$ & 0.32 & 0.32 & Typical value for PP \\
\hline$\nu_{23}$ & 0.028 & 0.142 & $\nu_{23}=\nu_{32}\left(E_{2} / E_{3}\right)$ \\
\hline$\nu_{13}=\nu_{31}$ & 0.125 & 0.39 & Experimental value \\
\hline$G_{12}(\mathrm{MPa})$ & 6548.94 & 1276.5 & $=E_{1} / 2\left(1+\nu_{12}\right)$ \\
\hline$G_{23}(\mathrm{MPa})$ & 729.57 & 656.7 & $=E_{2} / 2\left(1+\nu_{23}\right)$ \\
\hline$G_{31}(\mathrm{MPa})$ & 7684 & 1212.2 & $=E_{3} / 2\left(1+\nu_{31}\right)$ \\
\hline
\end{tabular}

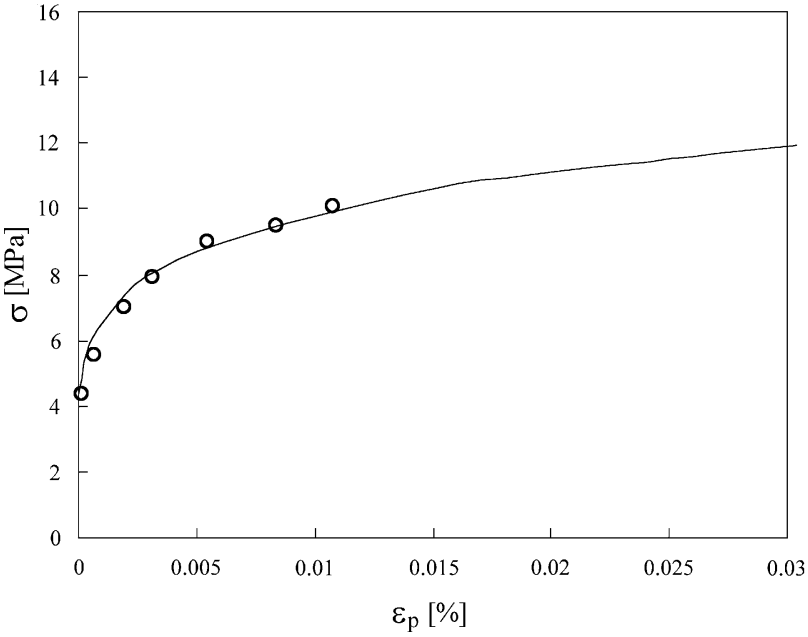

Fig. 6. Experimental points and the fitted Ramberg-Osgood curve.

closed with many experimental failure regions. For this section the peeling and shear stresses were analysed and plotted. Fig. 9 shows the peeling stresses along the section for an axial load of $2 \mathrm{kN}$. Again the stresses were higher for hybrid stacking than for solely PP/glass fibre composites in an edge region of about $1 \mathrm{~mm}$. The peak stresses were about $30 \%$ higher.

The higher stresses obtained for hybrid stacked joints are a consequence of the higher rotation and strains occurring in hybrid composites and the assumption that the stiffness modulii in the thickness direction were equal in the two laminates.

Shear stresses along the same section are shown in Fig. 10, for both composite stacking and the axial load of $2 \mathrm{kN}$. In this case the peak stresses observed in the edge for both types of staking are closed being the shear stresses for the hybrid stacking only slight higher. However, a significant difference was obtained for points distanced between 0.3 and $3 \mathrm{~mm}$ of the edge. Maximum differences were obtained at a distance $0.5 \mathrm{~mm}$ from the edge.

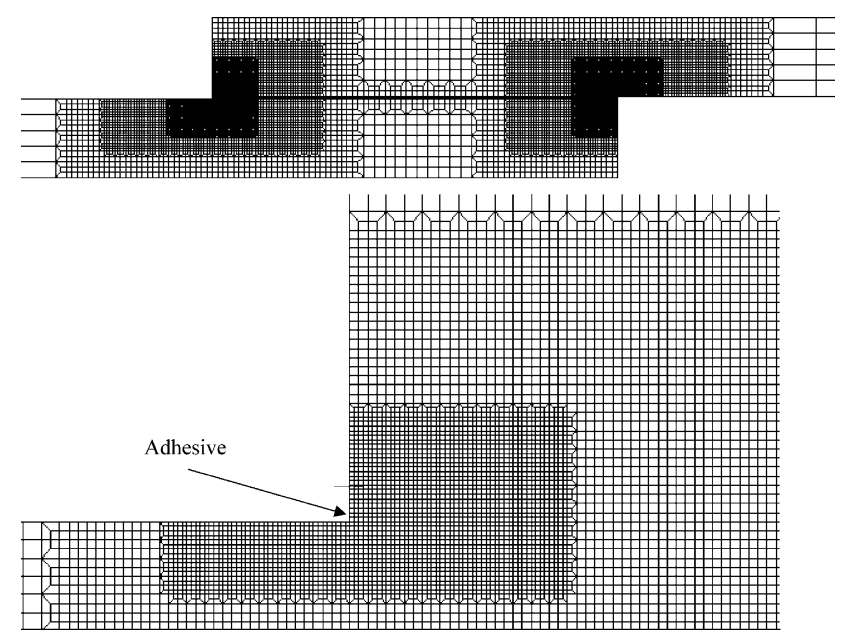

Fig. 7. Typical finite element mesh. 

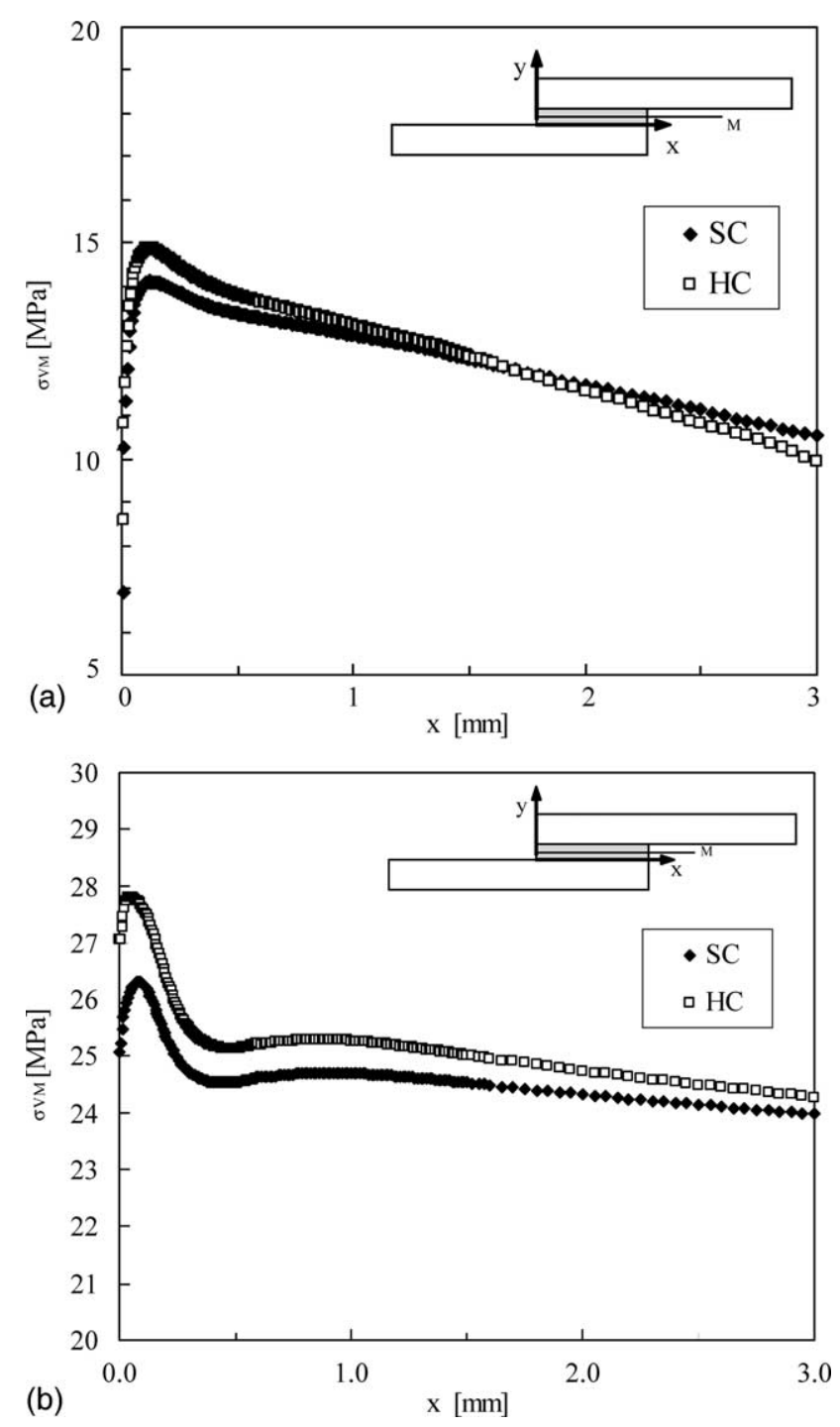

Fig. 8. (a) Von Mises stress along the mid-line of the adhesive. $P=2000 \mathrm{~N}$. (b) Von Mises stress along the mid-line of the adhesive. $P=8000 \mathrm{~N}$.

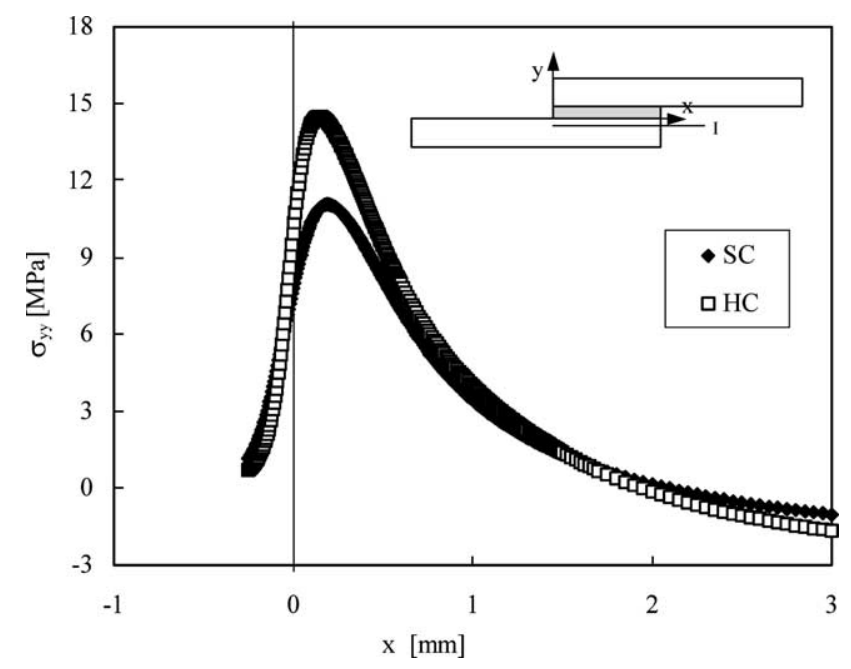

Fig. 9. $\sigma_{y y}$ stress along the line $y=-100 \mu \mathrm{m}, P=2000 \mathrm{~N}$.

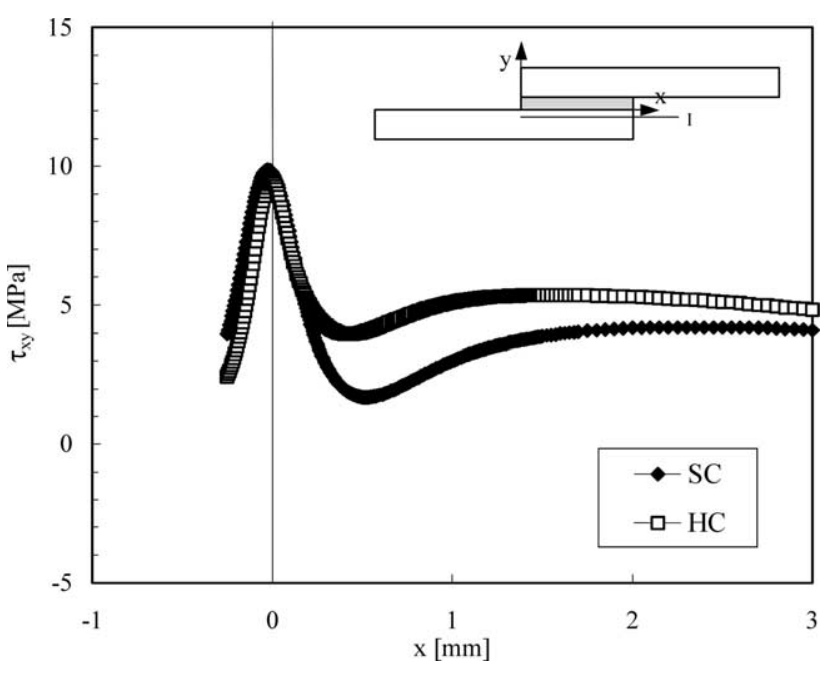

Fig. 10. Shear stress along the line $y=-100 \mu \mathrm{m}, P=2000 \mathrm{~N}$.

Despite the fact that numerical results will include some inaccuracies due to the assumption of homogeneous and a linear elastic behaviour for the adherends (put together with peeling strength tests), it is found that contrary to the expectations of the authors, adhesive joints involving flexible natural fibre hybrid stacking do not improve the strength of the joints (due to higher stresses in interface regions and lower interlaminar fracture toughness).

Joints with hybrid stacking and 0.12 volume fraction of natural fibre had static and fatigue strengths only approximately $10-15 \%$ lower than solely PP/glass fibre joint (Fig. 2). Thus these joints could be a potential alternative to solely PP/glass fibre joints if economical and the ecological factors are taken in account. Further studies are to be carried out on the stacking layer order effect, particularly the when the natural fibre is placed preferentially in the central zone of plate thickness.

\section{Conclusions}

- The fatigue strength of hybrid stacked joints is lower than the original thermoplastic composite joints and decreases with the natural fibre content;

- Peak stresses in critically referenced sections obtained by finite element analysis are significant higher in hybrid stacked fibre composites than in single fibre composites;

- Adhesive strengths obtained by DCB tests in single fibre composite laminates are significantly higher (28\%) than with PP/natural hybrid fibre sheets;

- Hybrid stacked composite joints could be a practical alternative to single fibre composite joints if economical costs and ecological factors are taken in account; 
- Further studies are suggested particularly using layer stacking with the natural fibre placed preferentially in the central zone of the plate thickness.

\section{Acknowledgements}

The authors would thank RTA-NATO, Support Programme Project P-128, for funding this work.

\section{References}

[1] Renton WJ, Vinson JR. Fatigue behavior of bonded joints in composite material structures. J Aircraft 1975;12(5):442-7.

[2] Renton WJ, Vinson JR. The efficient design of adhesive bonded joints. J Adhes 1975;7:175-93.

[3] Harris JA, Fay PA. Fatigue life evaluation of structural adhesives for automotive applications. Int J Adhes Adhes 1992;12(1):9-18.

[4] Ferreira JAM, Reis PN, Costa JDM, Richardson MOW. Fatigue behaviour of composite adhesive lap joints. Comp Sci Technol 2002; 62:1373-9.

[5] Chai H. Deformation and failure of adhesive bonds under shear loading. J Mater Sci 1993;28:4944-56.

[6] Lees WA. Stress distribution in-bonded joints: an exploration within a mathematical model. Int J Mater Product Technol 1987;2(2):168-81.

[7] Kairouz KC, Matthews FL. Strength and failure modes of bonded single lap joints between cross-ply adherends. Composites 1993; 24(6):475-84.
[8] Guess TR, Alfred RE, Gestle Jr FP. Comparison of lap shear test specimens. J Test Eval 1977;5(3):84-93.

[9] Mall S, Ramamurthy G. Effect of bond thickness on fracture and fatigue strength of adhesive bonded composite joints. Int J Adhes Adhes 1989;9(1):33-7.

[10] Ferreira JAM, Costa JDM, Reis PNB. Static and fatigue behaviour of glass-fibre-reinforced polypropylene composites. Theor Appl Fract Mech 1999;31:67-74.

[11] Ferreira JAM, Costa JDM, Reis PNB, Richardson MOW. Analysis of fatigue and damage in glass-fibre-reinforced polypropylene composite materials. Comp Sci Technol 1999;59: $1461-7$.

[12] ASTM D 5528-94a, Standard test method for mode I interlaminar fracture toughness of unidirectional fiber-reinforced polymer matrix composites. Annual Book of ASTM Standards. 1994.

[13] Hutchinson JW. A Course on Nonlinear Fracture Mechanics. Department of Solid Mechanics, The Technical University of Denmark; 1989.

[14] Williams JG. The fracture mechanics of delamination tests. Int J Strain Anal 1989;24(4):207-14.

[15] ISO 3268-1978 (F). Plastiques-Matieres renforcés au verre textileDetermination des caracteristiques en traction; 1978.

[16] ASTM E132-97. Standard test method for Poisson's ratio at room temperature; 1997.

[17] MARC User Information. Marc Analysis Research Corp., Palo Alto; 2000.

[18] Hildebrand M. Non-linear analysis and optimization of adhesively bonded single lap joints between fibre-reinforced plastics and metals. Int J Adhes Adhes 1994;14(4):261-7. 